Fifth International Conference on Sustainable Construction Materials and

Technologies. http://www.claisse.info/Proceedings.htm

\title{
INERT MATERIAL WITH BINDING RIM BY REACTIVE MILLING
}

\author{
Frank Schmidt-Döhl ${ }^{1}$, Gabriel Glück ${ }^{2}$, David Schulenberg ${ }^{3}$ \\ 1 TUHH B3, D 21071 Hamburg, schmidt-doehl@tuhh.de, University of \\ Technology Hamburg \\ 2 LV Baumanagement AG, Banksstraße 4, D 20097 Hamburg, \\ ga_glueck@yahoo.de \\ 3 TUHH B3, D 21071 Hamburg, david.schulenberg@tuhh.de, University of \\ Technology Hamburg
}

\begin{abstract}
The use of hydraulic binders with an inert core and reactive shell may be an opportunity to develop more efficient mineral building materials. Reactive milling is one method to obtain such structures, known as a method of mechanochemistry. Tests were performed using $\mathrm{CaO}$ and $\mathrm{CaCO}_{3}$ as calcium containing components and cristobalite, silica fume and quartz as silicon containing components as powders using a planetary ball mill. The reaction products were examined using Attenuated Total Reflection (ATR) IR spectroscopy and light microscopy. A very clear new formation of a group of peaks around $900 \mathrm{~cm}^{-1}$ (typical for a calciumsilicate) was observed for $\mathrm{CaO}$ and cristobalite. The $\mathrm{CaO} /$ silica fume and $\mathrm{CaO} /$ quartz pairs behave similarly in principle. The tests showed that it seems possible to produce a material with an inert core, for example quartz, and a reactive rim, for example calciumsilicate, using reactive milling.
\end{abstract}

Keywords: cement, core-shell structure, reactive milling

\section{INTRODUCTION}

Energy efficiency and the reduction of carbon dioxide emissions are important topics for the binder and concrete technology. The replacement of portland cement clinker using latent hydraulic components (e.g. blustfurnace slag, some fly ashes), pozzolanic (some fly ashes, silica fume) or inert components (lime stone powder) was widely used for improvements of binders in the last centuries and is now exhausted. The energy efficiency of the clinker production process has now nearly reached its optimum. So new ideas are needed. 
Hydraulic binders with an inert core and a reactive shell may be an opportunity to develop more efficient mineral building materials. It is not absolutely necessary that the whole volume of binder particles is reactive. Reactive milling is an opportunity to obtain such structures, known as a method of mechanochemistry (Heinike, 1984). During milling, structures of solid phases are disturbed, the chemical potential changes, surfaces are increased, particles dispersed and locally very high temperatures are generated. As a result the reactions of different components can be activated by a high mechanical energy input without the need for a bulk high temperature process. Tests were carried out by Glück (2017) which produced an inert material with a binding rim using reactive milling.

\section{MATERIALS AND METHODS}

\section{Materials}

Tests with $\mathrm{CaO}$ and $\mathrm{CaCO}_{3}$ as calcium containing components and cristobalite, silica fume and quartz as silicon containing components were performed. All the materials were in the form of powders. Burnt lime $(\mathrm{CaO})$ was supplied as a chemical reagent by Carl Roth $\mathrm{GmbH}$. It has a typical grain size of some microns. $\mathrm{CaCO}_{3}$ was a limestone powder from the Fels-Werke $\mathrm{GmbH}$, quarry Kaltes Tal. A sieved fraction with a $\mathrm{d}_{50}$ of 96 microns and a d90 of 154 microns was used. The cristobalite $\left(\mathrm{SiO}_{2}\right)$ was used in form of the product SIKRON SF4000 (Quarzwerke). This commercial product has a $\mathrm{d}_{50}$ of 5 microns and a $\mathrm{d}_{98}$ of 20 microns. Silica fume was used in form of the product Microsilica Grade $940 \mathrm{U}$ (Elkem). Silica fume mainly consists in amorphous $\mathrm{SiO}_{2}$. It was not possible to destroy the agglomerates (about 20 microns) during laser diffraction analysis. So we don't know the grain size of the primary particles. The quartz $\left(\mathrm{SiO}_{2}\right)$ was used in form of the product Millisil W3 (Quarzwerke). This commercial product has a $\mathrm{d}_{50}$ of 90 microns and a d 95 of 220 microns (data of the supplier). Pairs of a calcium containing component and a silicon containing component were examined in the milling tests (see chapter reactive milling).

\section{Particle Size Distribution}

The $\mathrm{CaCO}_{3}$, silica fume and cristobalite particle size distribution was measured via laser diffraction with a Mastersizer 3000 from Malvern. The dispersion liquid was ethanol. Measurements were analyzed with the Fraunhofer-theory.

\section{Light Microscopy}

All of the raw materials and some of the milled mixtures were investigated by light microscopy. Dispersions were examined with a polarization microscope D2500P from Leica in transmitted light. 


\section{Reactive Milling}

The reactive milling tests were performed with a planetary ball mill Fritsch Pulverisette 5. The mill was operated at $360 \mathrm{rpm}$. The mixed powders were milled in $80 \mathrm{ml}$ vessels. The temperature of the powders after the milling process was between $50{ }^{\circ} \mathrm{C}$ to $100{ }^{\circ} \mathrm{C}$. The following pairs of materials were investigated:

$\mathrm{CaO}$ and cristobalite (crystalline $\mathrm{SiO}_{2}$ )

$\mathrm{CaCO}_{3}$ and silica fume (amorphous $\mathrm{SiO}_{2}$ )

$\mathrm{CaO}$ and quartz (crystalline $\mathrm{SiO}_{2}$ )

In addition the pair $\mathrm{CaO}$ and silica fume was investigated.

The question if a reaction will take place or not, can be theoretically described by the change of the systems Gibbs energy $(\Delta \mathrm{G})$. If a reaction leads to a more negative Gibbs energy, the reaction will take place. However the reaction rate may be so slow, that the reaction is inhibited. So in addition chemical kinetics must be considered. Kinetics is strongly affected by temperature and catalysis. The reaction of burnt lime $(\mathrm{CaO})$ with quartz, cristobalite or silica fume $\left(\mathrm{SiO}_{2}\right)$ to belite $\left(\mathrm{C}_{2} \mathrm{~S}\right)$ has a negative $\Delta \mathrm{G}$. These reactions will run without consumption of energy, only the activation energy must be supplied. On the contrary, the reaction of limestone $\left(\mathrm{CaCO}_{3}\right)$ and silica fume $\left(\mathrm{SiO}_{2}\right)$ has a positive $\Delta \mathrm{G}$.

\section{Phase Analysis with ATR-Infrared Spectroscopy}

Infrared radiation can result in vibrations and rotations at an atomic scale. The radiation is absorbed at wavelengths that are characteristic for each functional groups. These groups can be identified with infrared-spectroscopy. In an IR-spectrum the absorption or transmission is displayed as a function of energy. In IR-spectroscopy often the so called wave number, the reciprocal of the wavelength is used as an energy unit.

In ATR-spectroscopy the attenuation of the evanescent wave during total reflection at interfaces is used. ATR IR spectroscopy is very sensitive to changes in the material surfaces, as the evanescent wave, produced by the reflection element of the ATR unit, only propagates some micrometers deep into the specimen. IR-analyses were performed with a Spectrum Two spectrometer (Perkin Elmer), with a single reflection diamond ATR system.

\section{RESULTS OF THE REACTIVE MILLING TESTS AND DISCUSSION}

In the first series of tests mixtures of $\mathrm{CaO} /$ cristobalite, $\mathrm{CaCO}_{3} /$ silica fume and $\mathrm{CaO} /$ quartz were milled with the ratios $20 / 80,40 / 60,60 / 40$ and $80 / 20$ per weight, and a duration of 5,10, 15, 20 and 30 minutes. Mixtures of $5 \mathrm{~g}$ each were milled with 3 steel balls ( $20 \mathrm{~mm}$ in diameter).

In the case of the $\mathrm{CaO} /$ cristobalite mixture a very clear new formation of a group with IR signals around $900 \mathrm{~cm}^{-1}$ was observed. This is typical for portland cement. In cement it results from the $\mathrm{Si}-\mathrm{O}$ vibrations in the nesosilicates $\mathrm{C}_{2} \mathrm{~S}$ and $\mathrm{C}_{3} \mathrm{~S}$ with $\mathrm{Q}^{0}$ structural elements. It can be assumed that in the tests described here, it is a result of a 
new formation of $\mathrm{C}_{2} \mathrm{~S}$. The signals were strongest in the 40/60 and 60/40 mixtures. The longer the milling time, the higher was the intensity. In the case of the $\mathrm{CaO} / q u a r t z$ mixture this new formation was also observable, but much smaller, due to the lower reactivity of quartz. The mixture of $\mathrm{CaCO}_{3}$ and silica fume shows no formation of a new phase. A type of fractionation during milling, changing the intensities could be observed, also in some other tests.

In the second series of tests mixtures of $\mathrm{CaO} /$ cristobalite, $\mathrm{CaCO}_{3} /$ silica fume and $\mathrm{CaO} /$ quartz were milled with the ratio $50 / 50$ per weight, with a duration of 10,20 and 30 minutes. Mixtures of $6 \mathrm{~g}$ each with an addition of $0.5 \mathrm{~g}$ water were milled with 3 steel balls $(20 \mathrm{~mm})$. In the $\mathrm{CaO} /$ cristobalite and $\mathrm{CaO}$ /quartz tests no new formation of a calciumsilicate was observed. Portlandite and probably calciumcarbonate was formed. The mixture $\mathrm{CaCO}_{3} /$ silica fume showed no reaction.

In the third series of tests $\mathrm{CaO} /$ cristobalite, $\mathrm{CaCO}_{3} /$ silica fume, $\mathrm{CaO}$ /quartz and $\mathrm{CaO} /$ silica fume mixtures were milled in a 50/50 weight ratio, with a duration of 15 , 30, 45, 60 and 90 minutes. Mixtures of $6 \mathrm{~g}$ each were milled with 3 steel balls $20 \mathrm{~mm}$ and 10 balls $10 \mathrm{~mm}$. The results are similar to those in series 1 . Figure 1 shows the new formation of signals around $900 \mathrm{~cm}^{-1}$, probably from $\mathrm{C}_{2} \mathrm{~S}$. The other signals in Figure 1 are related to cristobalite. $\mathrm{CaO}$ has only an incomplete peak (flank) at the low wavenumber end of the spectrum. $\mathrm{CaO} /$ quartz (Figure 2) and $\mathrm{CaO} /$ silica fume (Figure 3) mixtures also showed a new formation of signals in the $900 \mathrm{~cm}^{-1}$ range. In the $\mathrm{CaCO}_{3} /$ silica fume mixture no indications of a new formation occurs, only changes in intensities.

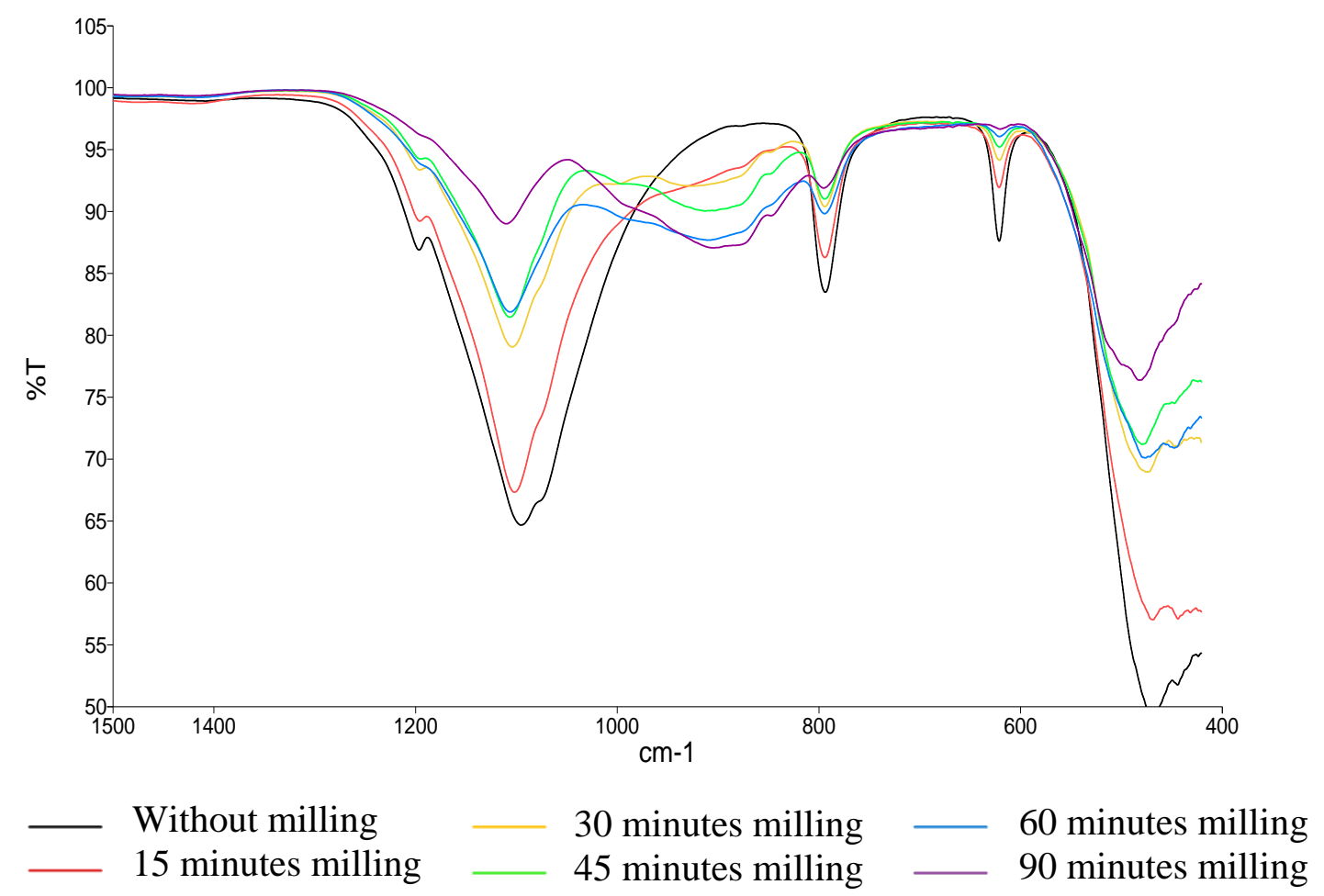


Figure 1. ATR-IR spectra of $50 / 50$ by weigth mixtures of $\mathrm{CaO} /$ cristobalite, with different milling duration. (Glück 2017)

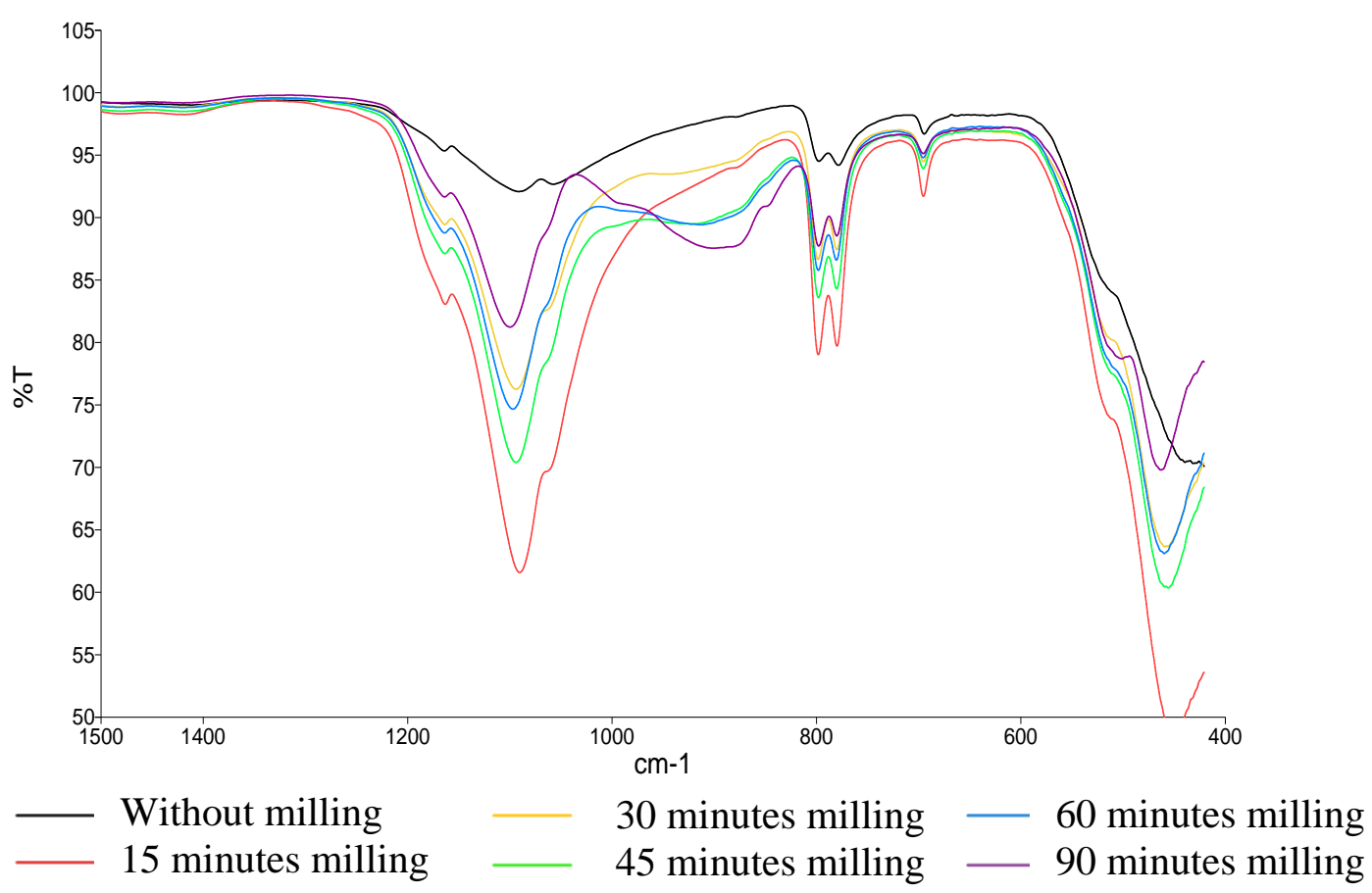

Figure 2. ATR-IR spectra of 50/50 mixtures of $\mathrm{CaO} /$ quartz, with different milling duration. (Glück 2017)

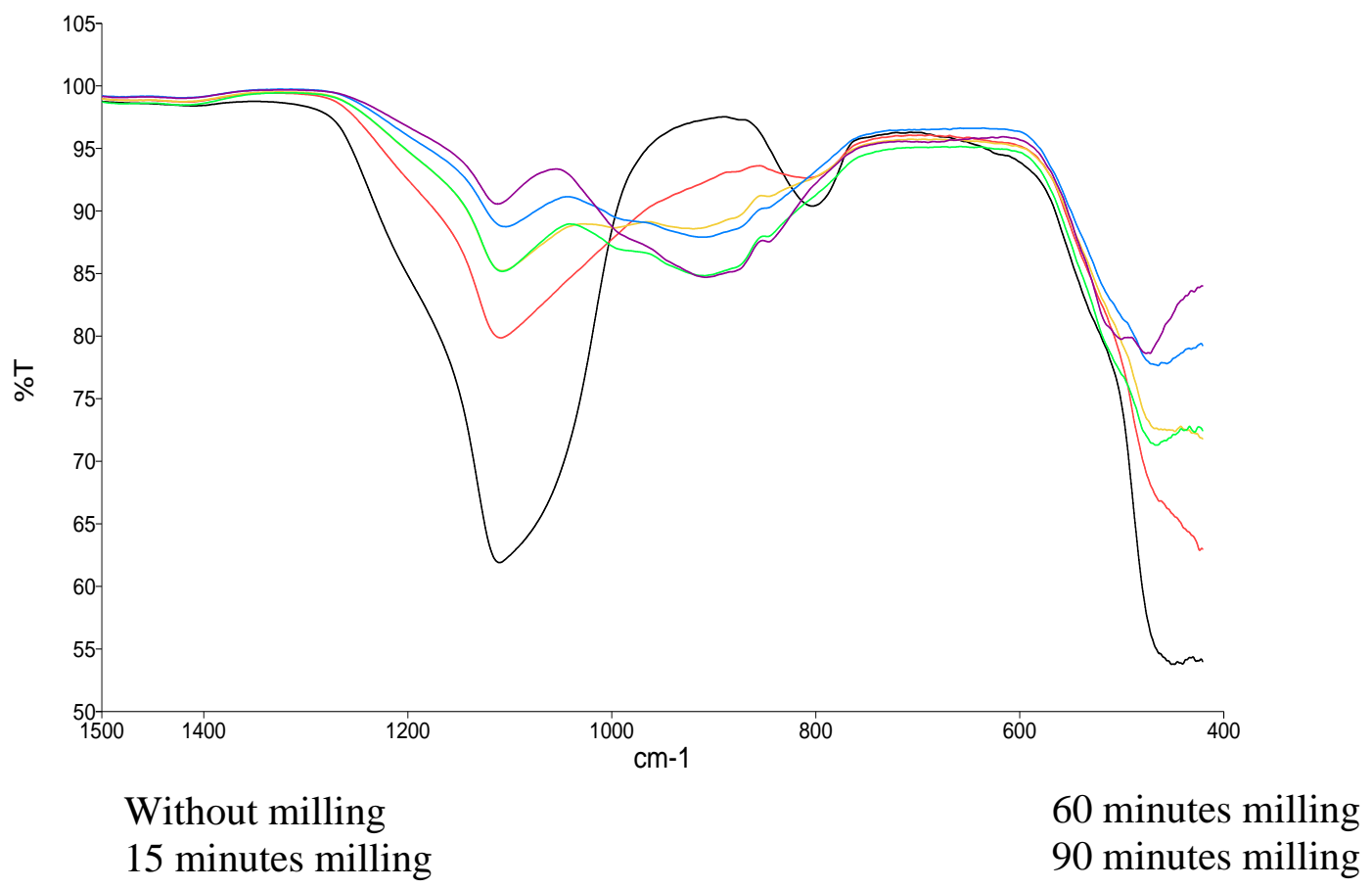




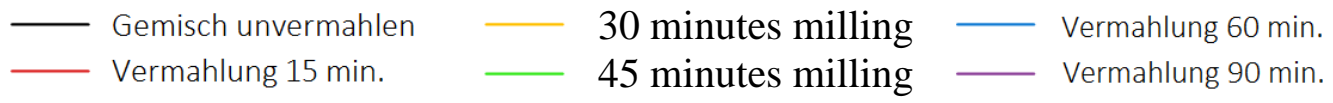

Figure 3. ATR-IR spectra of 50/50 mixtures of $\mathrm{CaO} /$ silica fume, with different milling duration. (Glück 2017)

The following images show the change of the core materials cristobalite (Figure 4) and quartz (Figure 5) by the milling with $\mathrm{CaO}$. The images of watery dispersions with a polycarboxylate (PCE) plasticizer were taken by a light microscope. It is evident that the surface of the particles has changed by coating or reaction with the $\mathrm{CaO}$. The IR spectra showed that there is a reaction.

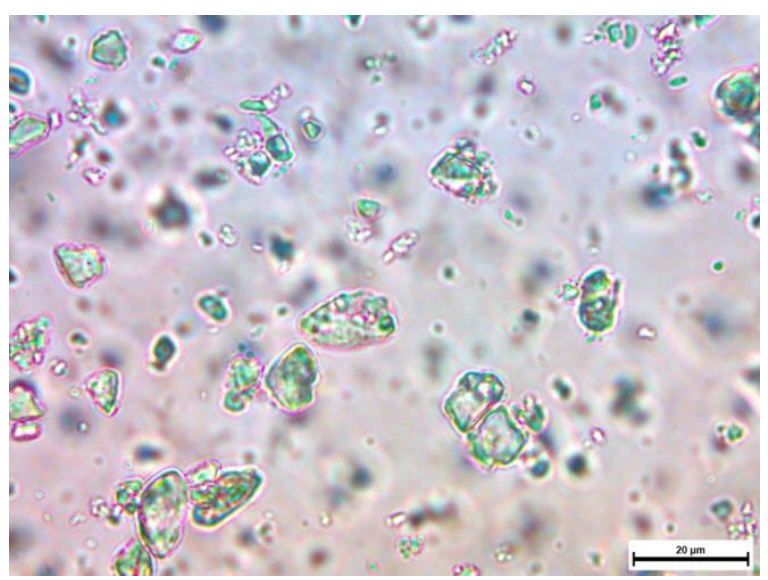

Figure 4. Left: watery dispersion of cristobalite. Right: mixture of cristobalite with $\mathrm{CaO}$ after 90 minutes milling. Scale in both cases 20 microns. (Glück 2017)
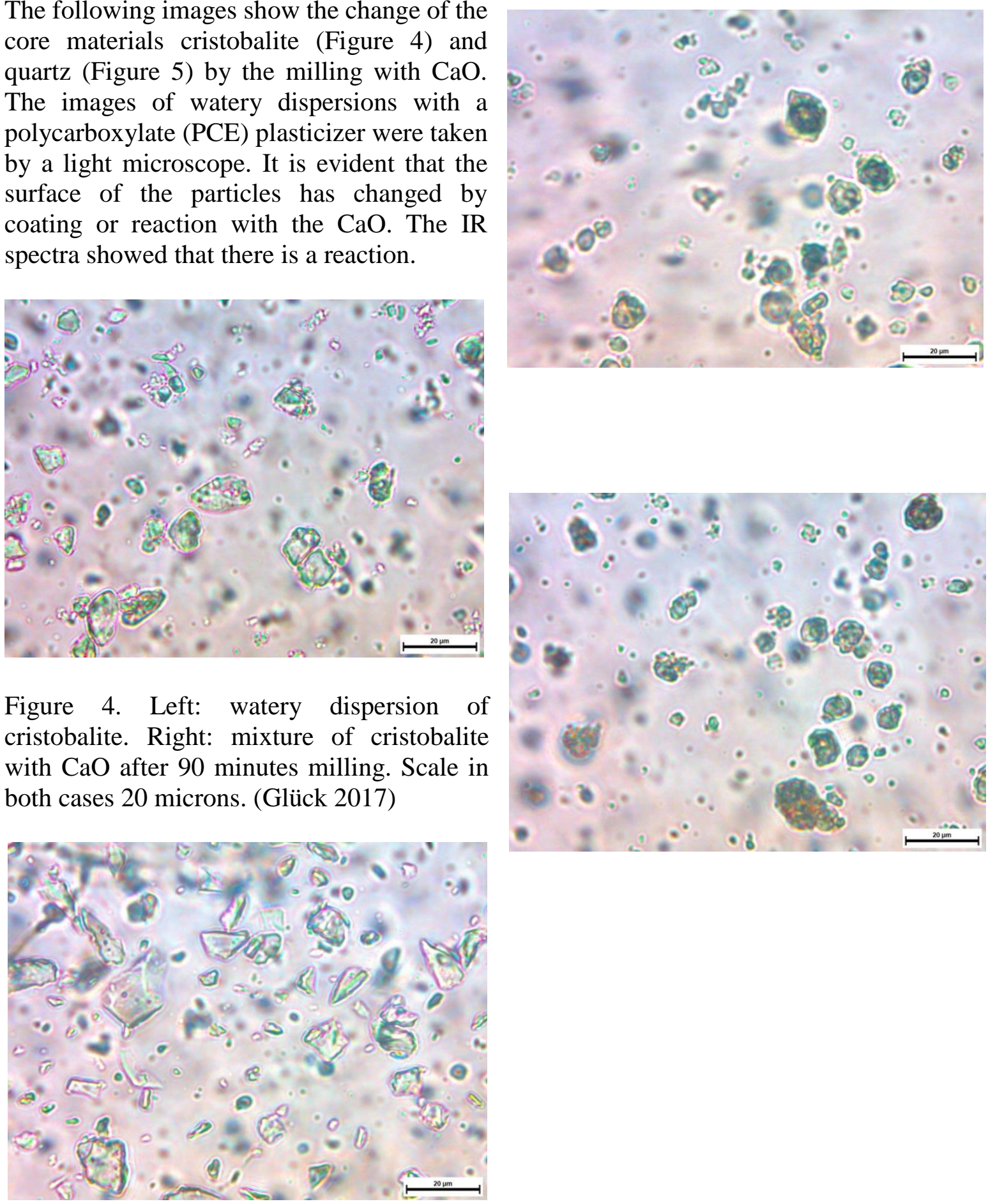
Figure 5. Left: watery dispersion of quartz. Right: mixture of quartz with $\mathrm{CaO}$ after 90 minutes milling. Scale in both cases 20 microns. (Glück 2017)

\section{CONCLUSIONS}

The tests showed that it seems possible to produce a material with an inert core, for example quartz, and a reactive rim, for example calciumsilicate, by reactive milling, for example together with $\mathrm{CaO}$. The $\mathrm{Q}^{0}$ silicate, produced by the process probably is $\mathrm{C}_{2} \mathrm{~S}$. A reaction between the surface of $\mathrm{CaCO}_{3}$ and $\mathrm{SiO}_{2}$-source by the milling could not be observed.

Reactive milling produces locally high temperatures without a classical high temperature process. The results show, that building material experts should keep reactive milling in mind, to produce core-shell structures with a reactive rim. Binders with core shell structure may be helpful to reduce both the energy demand and $\mathrm{CO}_{2-}$ emissions during production.

\section{REFERENCES}

Glück, G. (2017). Untersuchungen zu einem energieoptimierten Bindemittel, Masterthesis, University of Technology Hamburg.

Heinike, G. (1984). Tribochemistry, Akademie Verlag, Berlin. 